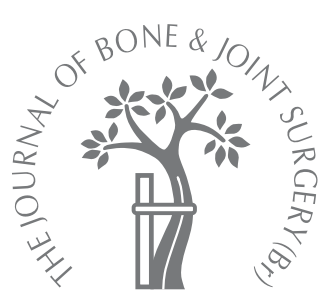

J. G. B. MacLean, S. K. Reddy

From Perth Royal Infirmary, Perth and Ninewells Hospital Medical School, Dundee, Scotland
I. G. B. MacLean, FRCS(Orth), Consultant Orthopaedic Surgeon Department of Orthopaedics, Perth Royal Infirmary,

Taymount Terrace, Perth PH1 1NX, UK.

In. K. Reddy, FRCS(Orth), MCh(Orth), Specialist Orthopaedic Registrar Department of Orthopaedics Ninewells Hospital, Dundee DD1 9SY, UK.

Correspondence should be sent to Mr J. G. B. MacLean; e-mail: Jamie.maclean@ tuht.scot.nhs.uk

(C)2006 British Editorial Society of Bone and Joint Surgery doi:10.1302/0301-620X.88B11. $17523 \$ 2.00$

$J$ Bone Joint Surg [Br] 2006;88-B:1497-501.

Received 7 December 2005.

Accepted after revision 14 June 2006

\section{The contralateral slip}

\author{
AN AVOIDABLE COMPLICATION AND INDICATION FOR \\ PROPHYLACTIC PINNING IN SLIPPED UPPER FEMORAL EPIPHYSIS
}

\begin{abstract}
Between July 1994 and June 2004, 60 patients with 76 slipped upper femoral epiphyses were managed within the adult trauma service of three hospitals. Treatment was by a single cannulated screw.
\end{abstract}

Of these cases, 53 were unilateral, in 17 of which uncomplicated prophylactic fixation of the contralateral hip was performed. Of the other 36 cases, nine presented with a subsequent slip despite ongoing out-patient care. The subsequent slip was unpredictable in timing and unrelated to the age at the initial slip. It was more often unstable and in one case avascular necrosis developed. The overall rate of avascular necrosis, although in accordance with the literature, was $60 \%$ in acute unstable slips with a slip angle greater than $40^{\circ}$.

In our experience, prophylactic fixation was safer than continued observation of the contralateral hip.

Slipped upper femoral epiphysis continues to be treated within adult trauma services despite the development of increasing numbers of specialist paediatric orthopaedic units. Our study was undertaken in a region where it is treated within the general trauma service of three hospitals. The operating surgeons were usually senior but only two had an expressed interest in paediatric orthopaedics. Our aim was to compare the outcome with that of published work and to identify whether our service required improvement.

\section{Patients and Methods}

We performed a retrospective review of the notes and radiographs of all patients with slipped upper femoral epiphysis who presented to Ninewells Hospital Dundee, Perth Royal Infirmary or Stracathro Hospital, Brechin between July 1994 and June 2004. Of 64 patients identified, 60 had complete records.

From their notes, they were classified according to the duration of symptoms ${ }^{1}$ and stability, as defined by Loder et al. ${ }^{2}$ Lateral radiographs were measured to determine the lateral slip angle, ${ }^{3,4}$ which was also measured on the post-operative film. The radiographs were examined for evidence of avascular necrosis (AVN) or chondrolysis.

There were 42 males with a mean age of 13.1 years (9 to 16.9 ) and 18 females with a mean age of 11.8 years (9 to 13.4 ). Seven patients had bilateral presentation, of whom one had hypothyroidism. This was the only patient with an endocrine abnormality. Of the 53 patients with unilateral slipped upper femoral epiphysis, 17 underwent prophylactic fixation of the unaffected hip at the same operation and 36 had fixation of the affected side only. Of these 36 patients, nine developed a slip in the contralateral hip which required stabilisation.

All the hips were stabilised by a single cannulated screw, except for one in which two screws were used.

\section{Results}

Over the ten-year study period, 76 slips were reported in our population of 475000,67 of which were diagnosed at initial presentation and nine presented subsequently. This constitutes an annual incidence of 1.6 per 100000 .

On presentation, 18 slips were acute, 20 acuteon-chronic and 38 chronic. According to the lateral radiograph, 43 were mild (mean lateral slip angle $19^{\circ}\left(5^{\circ}\right.$ to $\left.30^{\circ}\right)$ ), 25 moderate (mean lateral slip angle $38^{\circ}\left(32^{\circ}\right.$ to $\left.\left.60^{\circ}\right)\right)$ and eight were severe (mean lateral slip angle $67^{\circ}\left(62^{\circ}\right.$ to $\left.80^{\circ}\right)$ ). Of the 76 slips, 62 were stable (mean lateral slip angle $26^{\circ}\left(5^{\circ}\right.$ to $\left.\left.68^{\circ}\right)\right)$ and 14 unstable (mean lateral slip angle $46^{\circ}\left(5^{\circ}\right.$ to $\left.\left.80^{\circ}\right)\right)$. Of the 14 patients with unstable slips, eight were acute-on-chronic and six were acute, however nine gave a history of an identifiable trauma (Table I). 
Table I. Details of the 14 patients with unstable slips

\begin{tabular}{|c|c|c|c|c|c|c|}
\hline \multirow[b]{2}{*}{ Case } & \multirow[b]{2}{*}{ Presentation } & \multirow[b]{2}{*}{ Traumatic event } & \multirow{2}{*}{$\begin{array}{l}\text { Fixation } \\
\text { (hrs) }\end{array}$} & \multicolumn{3}{|c|}{ Lateral slip angle ( $\left.{ }^{\circ}\right)$} \\
\hline & & & & Pre-fixation & Post-fixation & Complications \\
\hline 1 & Acute & Jumped on & $>24$ & 60 & 30 & $\mathrm{AVN}^{*}$ \\
\hline 2 & Acute & None & $>24$ & 44 & 26 & AVN \\
\hline 3 & Acute & Skateboard & $<24$ & 62 & 54 & AVN \\
\hline 4 & Acute-on-chronic & None & $>24$ & 56 & 52 & Chondrolysis \\
\hline 5 & Acute & Football & $<24$ & 34 & 32 & None \\
\hline 6 & Acute-on-chronic & Fall & $<24$ & 34 & 22 & None \\
\hline 7 & Acute-on-chronic & Fall & $<24$ & 62 & 44 & None \\
\hline 8 & Acute-on-chronic & Trip, fall & $<24$ & 60 & 56 & None \\
\hline 9 & Acute-on-chronic & Fall & $>24$ & 42 & 40 & None \\
\hline 10 & Acute & Football & $<24$ & 65 & 48 & None \\
\hline 11 & Acute-on-chronic & None & $<24$ & 22 & 22 & None \\
\hline 12 & Acute & None & $<24$ & 48 & 32 & None \\
\hline 13 & Acute-on-chronic & None & $>24$ & 26 & 16 & None \\
\hline 14 & Acute-on-chronic & Slip, fall & $>24$ & 45 & 40 & None \\
\hline
\end{tabular}

*AVN, avascular necrosis

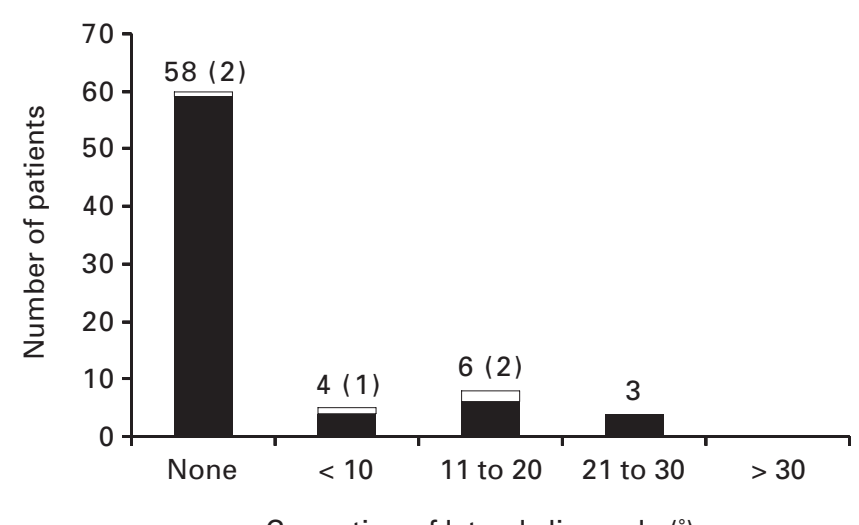

Correction of lateral slip angle $\left({ }^{\circ}\right)$

Fig. 1

Correction of the lateral slip angle. The number in parentheses are those hips which developed avascular necrosis.

Figure 1 illustrates the correction of the lateral slip angle and indicates that most patients had undergone fixation in situ. Only nine cases had correction of more than $10^{\circ}$. Of these, six had a lateral slip angle greater than $60^{\circ}$ at presentation. Some correction of the lateral slip angle was seen in the 14 unstable slips although in two who had minimal correction, the surgeon felt that no movement was present on screening during positioning of the patient. Of the 14 patients with an unstable slip there was an operating note of an attempt at gentle reduction by positioning in six, all of whom showed improvement in the lateral slip angle, although one developed AVN. In eight there was no recorded attempt at reduction, although the lateral slip angle improved in three and one developed AVN.

Avascular necrosis was seen in five hips in total. One patient, known to have hypothyroidism, developed bilateral AVN despite both slips being mild, stable and pinned in situ with no evidence of penetration of the pin. Table I gives the details of patients with unstable slips. The incidence of AVN in unstable slips was $21 \%$ (3 of 14) based on the history alone and $42 \%$ ( 3 of 7 ) when those with a change in lateral slip angle $<10^{\circ}$ were regarded as stable. Of five acute hips with a lateral slip angle $>40^{\circ}$, three developed AVN, an incidence of $60 \%$ in this subgroup. The mean change in the lateral slip angle was $19^{\circ}\left(8^{\circ}\right.$ to $\left.30^{\circ}\right)$ in patients with AVN and $8^{\circ}\left(0^{\circ}\right.$ to $\left.18^{\circ}\right)$ in uncomplicated cases. In all unstable cases, reduction of the displacement was incomplete and fixation was carried out with a mean residual lateral slip angle of $37^{\circ}\left(16^{\circ}\right.$ to $\left.56^{\circ}\right)$.

Operative stabilisation of unstable slips took place within 24 hours of presentation in eight patients and after this period in the remaining six. Of the three acute slips which developed AVN, two were fixed after 24 hours. Both the acute slips greater than $40^{\circ}$ which were uncomplicated, were treated within 24 hours.

There was one case of chondrolysis (Fig. 2) in an acuteon-chronic, moderately displaced unstable slip which had been pinned with minimal correction after 24 hours. Penetration of the screw was thought to be the underlying cause.

Seven cases were bilateral at the initial presentation and nine were seen later, an overall incidence of $27 \%$ (16 of 60 ). Table II gives the details of the nine patients with subsequent contralateral slipped epiphysis. Their gender and age distribution were not significantly different from those of the whole group. The mean interval between the first and subsequent slip was 12.9 months (2 to 33 ). The lateral slip angle between the slips was similar in five cases, but the subsequent slip was greater in three. Of the nine subsequent slips, three were unstable compared with one of the initial slips. In eight of the patients with a subsequent slip this was acute at presentation compared with only one of the initial slips. Figure 3 illustrates a patient who developed AVN in his right hip after uncomplicated treatment of the left hip six months earlier (Figs 3a and 3b). The lateral slip angle 


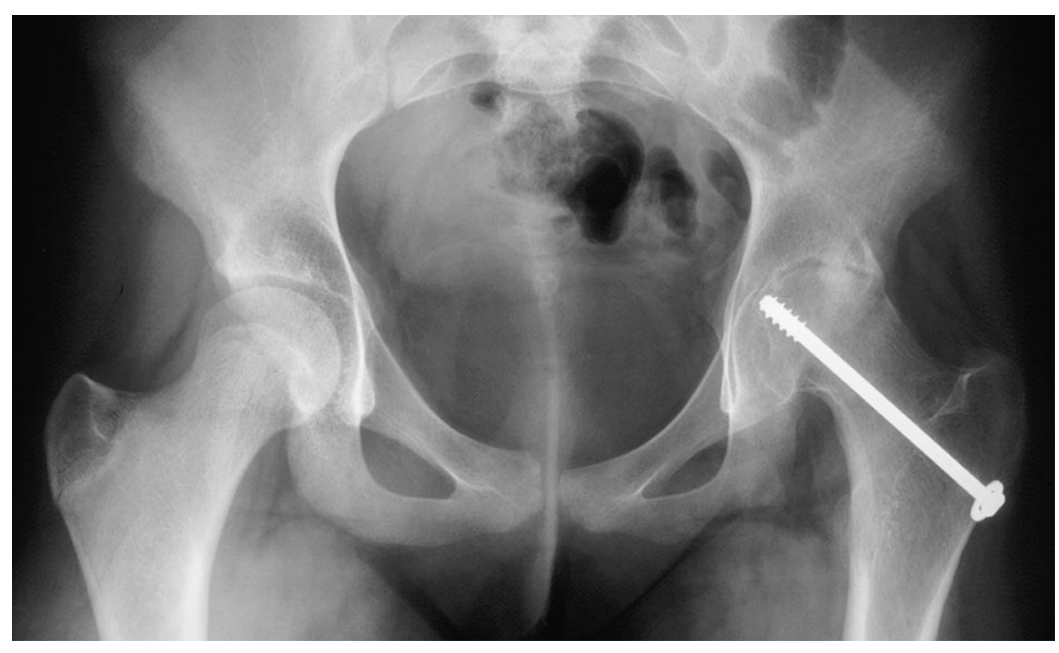

Fig. 2

Radiograph showing chondrolysis after persistent penetration of the pin.

Table II. Details of the nine patients with subsequent contralateral slipped upper femoral epiphysis

\begin{tabular}{|c|c|c|c|c|c|c|c|c|}
\hline \multirow[b]{2}{*}{ Case } & \multirow[b]{2}{*}{ Gender } & \multirow[b]{2}{*}{$\begin{array}{l}\text { Age at first } \\
\text { presentation (yrs) }\end{array}$} & \multirow[b]{2}{*}{$\begin{array}{l}\text { Interval between } \\
\text { slips (mths) }\end{array}$} & \multicolumn{2}{|c|}{ Lateral slip angle $\left({ }^{\circ}\right)$} & \multicolumn{2}{|l|}{ Stability } & \multirow[b]{2}{*}{ Complications } \\
\hline & & & & First slip & $\begin{array}{l}\text { Subsequent } \\
\text { slip }\end{array}$ & First slip & $\begin{array}{l}\text { Subsequent } \\
\text { slip }\end{array}$ & \\
\hline 1 & M & 13.2 & 27 & 22 & 18 & Stable & Stable & - \\
\hline 2 & M & 14.8 & 14 & 40 & 68 & Stable & Stable & - \\
\hline 3 & $\mathrm{~F}$ & 11.8 & 2 & 18 & 16 & Stable & Stable & - \\
\hline 4 & M & 14.4 & 6 & 26 & 44 & Unstable & Unstable & $\mathrm{AVN}^{*}$ \\
\hline 5 & M & 9.0 & 33 & 36 & 5 & Stable & Stable & - \\
\hline 6 & M & 13.8 & 7 & 30 & 28 & Stable & Stable & - \\
\hline 7 & $\mathrm{~F}$ & 13.4 & 8 & 28 & 22 & Stable & Stable & - \\
\hline 8 & $\mathrm{~F}$ & 11.5 & 6 & 28 & 22 & Stable & Unstable & - \\
\hline 9 & $\mathrm{~F}$ & 11.5 & 13 & 18 & 26 & Stable & Unstable & - \\
\hline
\end{tabular}

had been reduced by gentle manipulation and AVN ensued (Figs $3 \mathrm{c}$ to $3 \mathrm{e}$ ).

\section{Discussion}

The age and gender distribution, presentation and severity, is compatable with pooled epidemiological data. ${ }^{5}$

We recognise that the lateral slip angle is not a precise measurement, but it is regarded as a good reflection of the magnitude of the slip. ${ }^{6}$ In nine patients there was improvement in the lateral slip angle with a record of a conscious effort to improve the position in six of these. The numbers of patients are insufficient to comment on whether manipulative reduction of the slip is safe.

The change in the lateral slip angle is related to instability and in displaced, unstable cases some change in position is inevitable. $^{7}$

Avascular necrosis occurred in three acute unstable slips in which there was some correction of the lateral slip angle. The case of bilateral AVN which occurred in a stable minor slip was thought to be due to the associated hypothyroidism rather than to the treatment.

Our incidence of AVN in unstable slips is between $21 \%$, based on the history, and $42 \%$ when the history and mobil- ity of the physis, demonstrated by a change in the lateral slip angle, are considered. This compares with $47 \%$ in the series of Loder et al. ${ }^{2}$

Prophylactic fixation of the unaffected side is controversial, except in the presence of an endocrine disorder. With the exception of a patient in whom a technical error caused chondrolysis, the remaining 92 cannulated screws were inserted without complication. There were no problems in the 17 patients who underwent prophylactic fixation. The positioning of the screw in these patients was straightforward compared with those in whom displacement had occurred.

Central to the debate on prophylactic fixation is the true incidence of bilaterality. There is no agreed figure for bilaterality but Schmitz ${ }^{8}$ in a meta-analysis of seven studies published between 1988 and 2002, suggested a figure of $29 \%$ - this does not include, however, those patients in whom radiological changes in adulthood have been interpreted as representative of an undiagnosed contralateral slip. Hägglund et $\mathrm{al}^{9}$ observed an additional $40 \%$ of contralateral slips when radiographs were observed at longterm follow-up of 16 to 66 years, and osteoarthritic changes were observed in a quarter of these. 


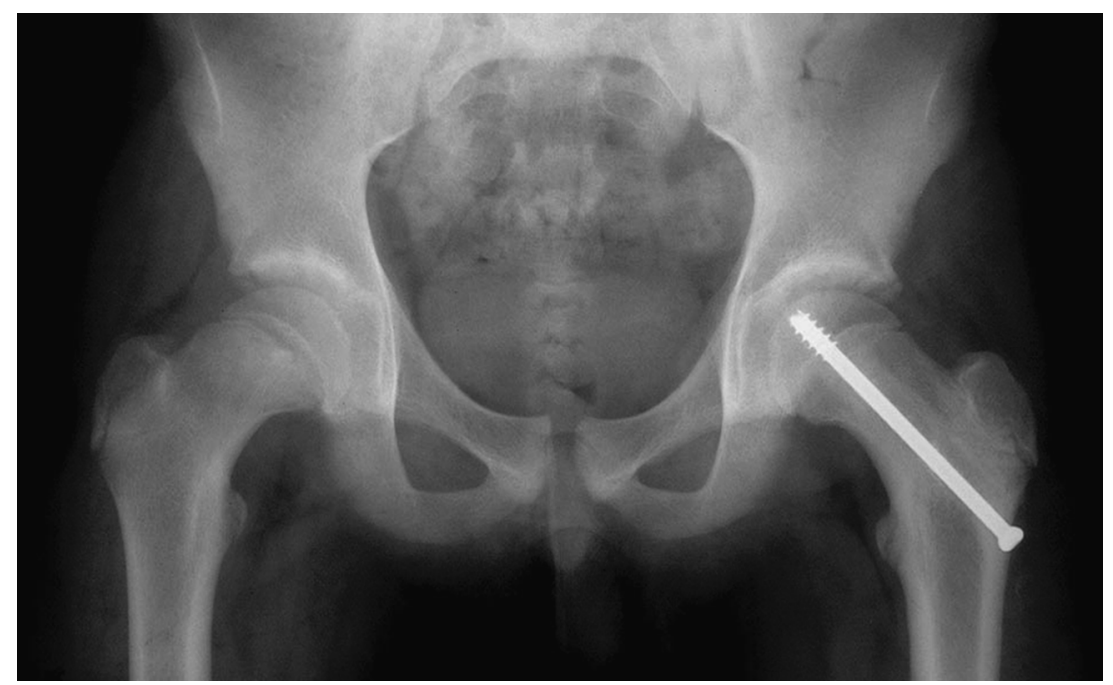

Fig. 3a

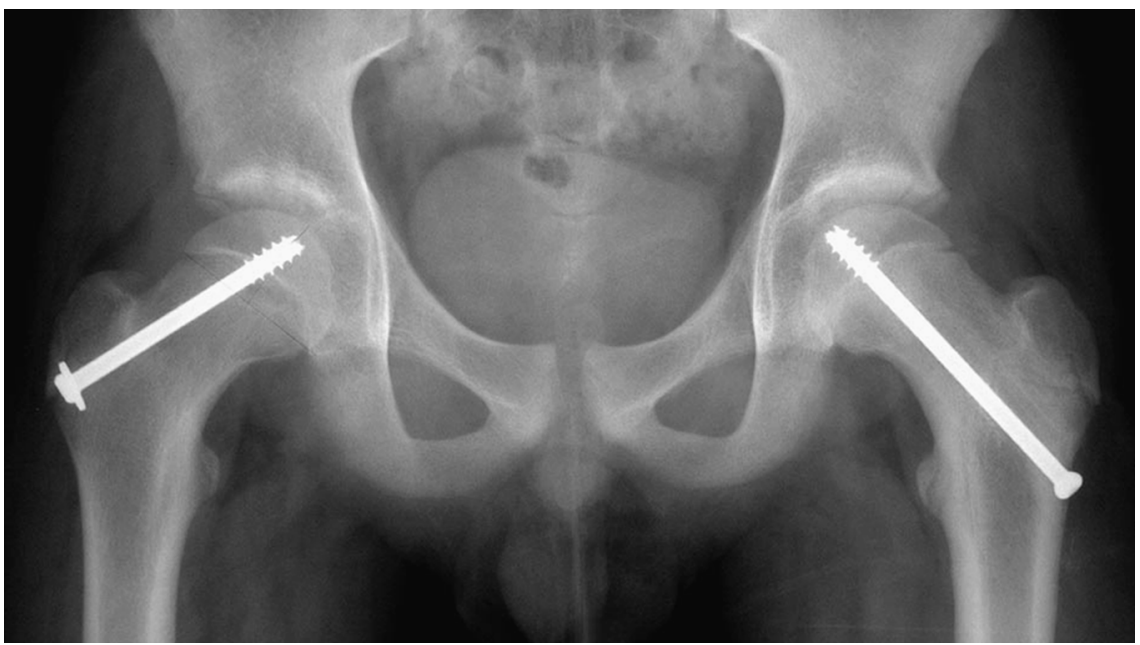

Fig. 3c

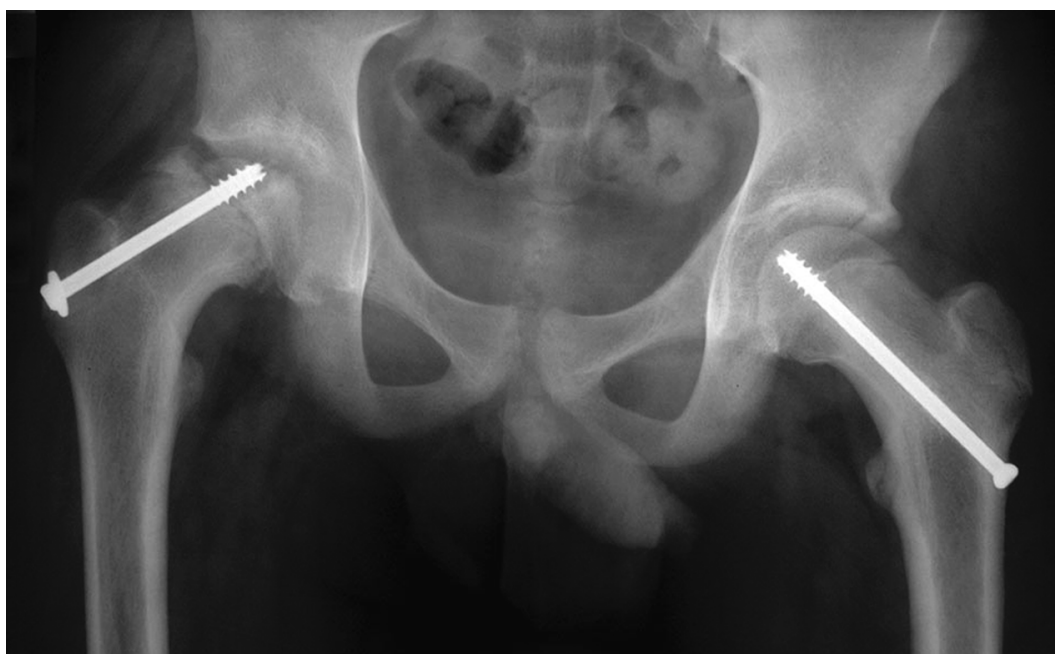

Fig. 3e

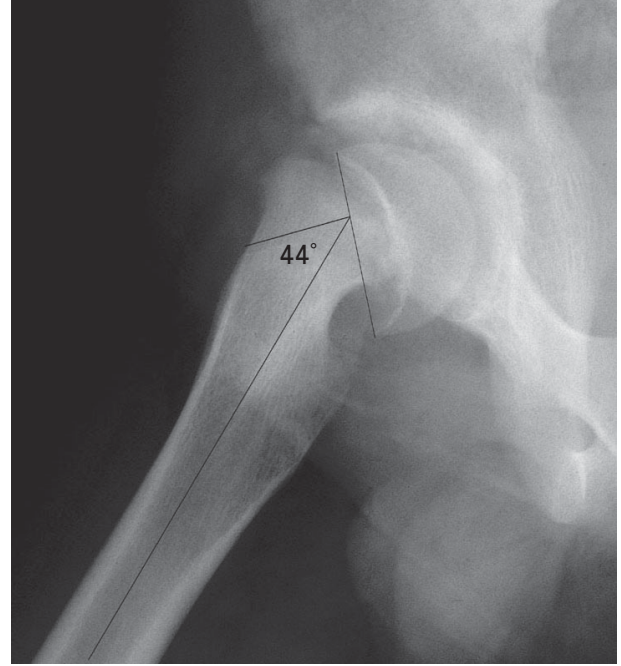

Fig. 3b

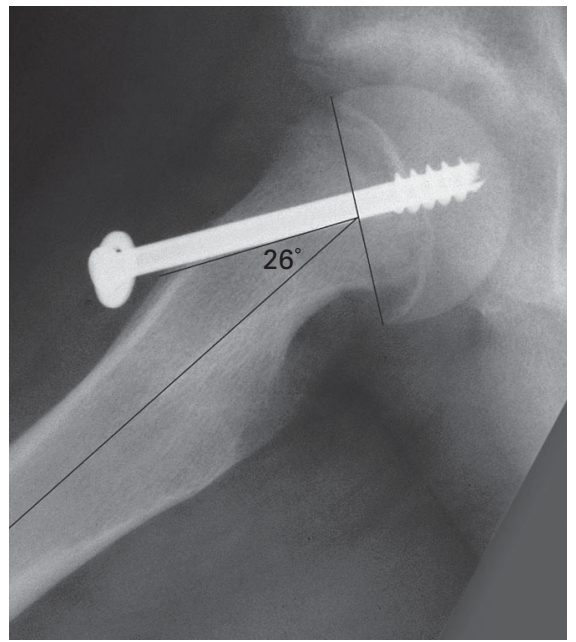

Fig. 3d

Radiographs showing a) a sequential slip at presentation six months after fixation of the initial slip; b) the sequential slip on a lateral view; c) the sequential slip after fixation; d) after fixation on a lateral view and e) avascular necrosis after fixation 
Our incidence of bilaterality was $11.7 \%$ (7 of 60 ) at the initial presentation and $15 \%$ (9 of 60 ) subsequently, giving a combined total of $27 \%$. This compares with the $9 \%$ initially and $12 \%$ subsequently, reported by Hägglund et $\mathrm{al}^{9}$ and the $19 \%$ incidence of subsequent slips when data from various studies were pooled. ${ }^{5}$ It should be recognised however that the nine subsequent slips in our series occurred in the 36 patients who were observed and who had not undergone prophylactic or simultaneous fixation and so the incidence of subsequent slips we observed was actually $25 \%$. Moreover, the subsequent slip was often more severe than the original and was unpredictable in its onset. The case of AVN was an avoidable complication.

Patient education is critical to ensure early presentation to hospital for symptoms in the contralateral hip, but comprehension and acceptance of advice are variable. All the patients with subsequent slips were under out-patient review at the time, but failed to present early, despite their previous experience.

Other issues in patients under observation are the period and level of activity restriction to be advised. Avoidance of contact sports may be necessary throughout adolescence. Such a problem is greatly reduced when prophylactic pinning is undertaken.

The Billings view ${ }^{10}$ may enable displacement to be detected earlier and its application to the contralateral hip at initial presentation may influence the decision whether to stabilise the hip or not. Through its reproducibility, the Billings view is attractive as a means of monitoring those hips under observation. Reproducibility of review radiographs may be central to the early diagnosis of a slip, particularly as contralateral slips may be asymptomatic. Unfortunately, in most centres radiographers are either unaware of the Billings view or have limited experience in performing it. Furthermore, performing it on a three- to four-monthly basis for up to two years, as suggested by Jerre et $\mathrm{al}^{11}$ raises economical, radiation and logistical questions. The number of subsequent radiographs after prophylactic pinning is significantly less.

Stabilisation by a single cannulated screw was shown to be a safe procedure with a very low rate of complications and, since this was achieved by non-paediatric orthopaedic surgeons in an adult trauma setting, it suggests that such outcomes are reproducible outside childrens' hospitals.

Our first conclusion is that, while most cases were treated effectively within an adult trauma service, there is a case to be made for specialist referral or at least discussion, for the moderate or severe unstable subgroup in whom the incidence of complications is significant and the subsequent management likely to be by a paediatric orthopaedic surgeon. Secondly, when considering the risks of contemporary fixation techniques as practised by a variety of surgeons in the three hospitals, prophylactic fixation of the contralateral hip was safer than continued observation.

We believe that a policy of prophylactic fixation combined with early recognition and discussion or referral of the severe unstable slip will improve the outcome.

No benefits in any form have been received or will be received from a commercial party related directly or indirectly to the subject of this article.

\section{References}

1. Fahey JJ, O'Brien ET. Acute slipped capital femoral epiphysis: review of the literature and report of ten cases. J Bone Joint Surg [Am] 1965;47-A:1105-27.

2. Loder RT, Richards BS, Shapiro PS, Reznick LR, Aronson DD. Acute slipped capital femoral epiphysis: the importance of physeal stability. J Bone Joint Surg [Am] 1993;75-A:1134-40.

3. Wilson PD. The treatment of slipping of the upper femoral epiphysis with minimal displacement. J Bone Joint Surg 1938;20:379-99.

4. Southwick W0. Osteotomy through the lesser trochanter for slipped capital femoral epiphysis. J Bone Joint Surg [Am] 1967;49-A:807-35.

5. Castro FP Jr, Bennett JT, Doulens KBS. Epidemiological perspective on prophylactic pinning in patients with slipped capital femoral epiphysis. J Paediatr Orthop 2000;20:745-8.

6. Loder RT, Blakemore LC, Farley FA, Laidlaw AT. Measurement variability of slipped capital femoral epiphysis. J Orth Surg 1999;7:33-42.

7. Schmidt TL, Cimino WG, Seidel FG. Allograft epiphysiodesis for slipped capital femoral epiphysis. Clin Orthop 1996;322:61-76.

8. Schmitz M. Slipped capital femoral epiphysis. American Academy of Orthopaedic Surgeons monograph 2002; chapter 2:31.

9. Hägglund G, Hansson LI, Ordeberg G, Sandström S. Bilaterality in slipped upper femoral epiphysis. J Bone Joint Surg [Br] 1988;70-B:179-81.

10. Billing L, Eklöt 0. Slip of the capital femoral epiphysis: revival of a method assess ment. Pediat Radiol 1984;14:413-18.

11. Jerre R, Billing L, Hansson G, Wallin J. The contralateral hip in patients primarily treated for unilateral slipped upper femoral epiphysis. J Bone Joint Surg [Br]1994;76B.563-7. 